\title{
Scalp-ear-nipple syndrome
}

INSERM

\section{Source}

INSERM. (1999). Orphanet: an online rare disease and orphan drug data base. Scalp-earnipple syndrome. ORPHA:2036

Scalp-ear-nipple syndrome is characterised by the following triad: areas of hairless raw skin over the scalp (present at birth and healing during childhood), prominent, hypoplastic ears with almost absent pinnae, and bilateral amastia. Thirty cases have been described so far. Renal and urinary tract abnormalities, as well as cataract, have also been observed. Transmission is autosomal dominant. 